\title{
CRITERIA SYSTEM OF EMERGENCY SITUATIONS RISKS ASSESSMENT IN THE BALTIC SEA PORTS
}

\author{
Darius Bazaras $^{1}$, Ramūnas Palšaitis ${ }^{2}$, Artūras Petraška ${ }^{3}$, Andrejs Zvaigzne ${ }^{4}$ \\ ${ }^{1}$ Transport Engineering Faculty, Vilnius Gediminas Technical University \\ Plytinès 27, Vilnius LT-10105, Lithuania \\ I+37069934797,darius.bazaras@vgtu.lt \\ 2+37069816448,ramunas.palsaitis@vgtu.lt \\ 3+37068212742,arturas@transvelas.lt \\ ${ }^{4}$ Latvian Maritime Academy \\ Riga, Latvia, 12-k Flotes Street, LV-1016 \\ +37129478533, andrejs.zvaigzne@latja.lv
}

\begin{abstract}
This paper reviews the principles of transportation risk assessment in the Baltic Sea ports and hinterland. The essential steps of assessment are the identification of primary criterions, the determining the underlying criterion groups and quantitative assessment of international environment indicators and nature, infrastructure indicators and organizational indicators on the basis of the multiple-criteria evaluation methods. Designed system of criteria creates a possibility for objective evaluation of risk management processes and allows planning objectively long-term risk management strategy in the ports according to certain economic development circumstances.
\end{abstract}

Keywords: Ports; criteria system; risk analysis; planning

\section{Introduction}

Enlargement of international business and economic relations between countries are directly connected with the growths of international cargo transportation. Ports located in the Eastern side or Baltic Sea act as a mediator in the expansion of trade connections of the most important transportation corridors between East and West.

Significance of the biggest BSR ports as transport system hubs can be extended if it will be generated as safe and more favourable environment for business transforming ports as transit points to the logistics services. Transportation security, cargo safety and cost are the main factors influencing transit flows territorial distribution and stability. In pursuance to enhance the Baltic states importance in the European business context it must be created more liberal conditions for the transit cargo transportation through the BSR countries states ports and the shaping of public policies and plans that either modify the causes of disasters or mitigate their effects on people, property, and infrastructure.

The biggest part of scientists are analysing the transport from the point of economic affectivity, country incomes from the of the usage infrastructure and transit transport management affectivity (Lopez et al., 2009; Litvinenko and Palsaitis, 2006). Competition effect on European public transport systems (on transit transport) was analysed (Karlaftis, 2009; Bazaras and Palsaitis, 2011).

Another issue at ports is the effectivity of their connections to the remainder of the country's transport infrastructure, such as rail and road. It is essential to better understand and apply risk analysis in the ports and assessment methods in mitigating accident risks and areas adjacent to these.

Risk assessments are very important to both logistics operators and Rescue Services and other Civil Protection, such as Customs, Border Guard, Coast Guard and Police and environmental agencies. Effective transportation and the transportation safety risk management in transport hubs can increase interoperability in transporting goods and persons in North-South and East-West connections based on increased capacity of transport and logistics actors.

For these reasons there is necessity to make the BSR ports with hinterland infrastructure complex activities and service quality analysis in parallel with the analysis of the improvement of the interoperability of resources in case of emergencies and created the model for an all involved actors resource and risk management in emergency situations. 


\section{International Project HAZARD as the Foundation for Scientific Research and Data}

The problem aspects analysed in this publication cover diverse types of risks and factors pertaining to accidents in seaports. The ongoing international project HAZARD of the BSR INTERREG program provides favourable conditions to assess situations under analysis, data collection and formulation of respective scientific assumptions. To briefly present the project, it is worth noting that ports, terminals and storage facilities are often located close to residential areas, thus potentially exposing a large number of people to the consequences of accidents. The HAZARD project deals with these concerns by bringing together rescue services, other authorities, logistics operators and established knowledge partners.

HAZARD project aims at mitigating the effects of emergencies in major seaports in the Baltic Sea Region. The types of safety and security emergency include, for example, leakages of hazardous materials, fires on passenger ships at port, oil spills in port areas as well as explosions of gases or chemicals.

HAZARD brings together Rescue Services, other authorities, logistics operators and established knowledge partners. HAZARD enables better preparedness, coordination and communication, more efficient actions to reduce damages and loss of life in emergencies, and handling of post-emergency situations by improving:

- $\quad$ harmonization and implementation of safety and security codes, standards and regulations;

- interoperability of resources through joint exercises;

- communication between key actors and towards the public;

- the use of risk analysis methods;

- $\quad$ adoption of new technologies.

The project duration is 36 months (spring 2016 - spring 2019) and the total budget is $4.3 \mathrm{M} €$, which is partly funded by the EU's INTERREG Baltic Sea Region Programme.

\section{Conceptual Provisions and Formalized Foreground Multiple Criteria Analysis for the Potential Emergency Situations Risks Management}

The complete risk analysis and assessment methods in mitigating accident risks in seaports and areas adjacent to these management life cycle includes the shaping of public policies and plans that either modify the causes of accident risks or mitigate their effects on people, property, and infrastructure.

The most common and relevant phases of emergency situations are mitigation, preparedness, response and recovery. The total accident risk in the port and ports hinterland management cycle includes prevention mitigation, preparedness, response/recovery and rehabilitation / reconstruction phases. These phases are described in flood risk management cycle (Van Veen et al., 2014) and disaster management cycle (Palukuri and Jain, 2014).

The mitigation and preparedness phases in the ports occur as risk management improvements are made in anticipation of a risk event. Developmental considerations play a key role in contributing to the mitigation and preparation of a port liable structures and port municipality government to effectively confront a disaster risk. As a disaster risk occurs, disaster management actors, in particular humanitarian organizations become involved in the immediate response and long-term recovery phases.

There are now quite many EU policy areas on built environment contributing to disaster risk management. EU Regulations and Directives take the major part of these EU strategies, legislation or programmes that are related to the disaster risk management and Member States (one of them is Lithuania) must comply with these legislative provisions (White Paper, 2011). The programs will support multimodal transport safety issues including protection from emergencies and accidents (including hazardous substances) associated with transport to reduce risk to human life and environment (Batarliené, 2008; HAZARD Project...).

During the analysis of transit transport flows distribution through ports it must be considered the protection from emergencies and accidents and quality of transportation services in the TEN-T ports, whosoever particularly influence transit flows territorial distribution.

At the macro level transit cargo transportation risks in the East-West transport corridor must be analyzed from the dimension of ports global competition.

In the case of comparison separate ports competition in the region must be performed more detail of factors groups (service quality, safety, security and other) influencing the transit transportation batching. In the existing enlarged terrorism emergency situation, it is essential to range whole emergency risks factors considering to their influence to the ports competition for the transit goods transportation 
attractiveness. Thereto for the separate groups of risk factors must be performed rating of main components.

Lately, it is highly stressed how promising the quantitative evaluation is in general; therefore, the objectives of its application in evaluation of transit international environment components are also relevant.

As the essential point for the solution of port competition an attraction level must be indicated transit transport environment analysis, initial risk components identification, formation and formulation. On that basis must be formulated compound quantitative estimation principles, valid evaluation methods and created usable models. Models oriented towards the results of quantitative evaluation enable to perform emergency situations risks in the different transport corridors, transit countries and alternative routes simulation and on the quantitative international and macro-environment assessment to formulate possible development scenarios. On the basis of the formulization emergency risks components and algorimization of the quantitative evaluation process it is possible to solve optimization problems. Thus the prepared methodology is an important tool to grant the complex theoretical validation of strategic decisions of country transport system and transit subsystem development.

During the formulization emergency situations risks factors it must be determined dependence from the whole influencing indicators, including their action directions such as port and hinterland infrastructure, human resources activities, environment and natural factors, global economic transformations. Multi-criteria system for choosing effective risk management in the ports could be used.

\section{Assessment of Emergency Risks Factors}

Evaluation of emergency situations risk management must be connected with the criteria system, which allows to identify optimal risk management strategy (Bazaras et al., 2013).

Different variable parameters in the assessment of emergency risks factors will be indicated by $X_{1}$, $X_{2}, \ldots, X_{n}$; parameters determining the risk management process in progress will be indicated by $Z_{1}, Z_{2}, \ldots$, $Z_{m}$, and variable parameters of the exit from the risk management improvements process will be indicated by $Y_{1}, Y_{2}, \ldots, Y_{s}$ (Figure 1). Then initial random quantities marked by $X_{1}, X_{2}, \ldots, X_{n}$ will be analysed as components of the random vector $X$, the random quantities $Z_{1}, Z_{2}, \ldots, Z_{m}$ - as components of the random vector $Z$ and the exit random quantities $Y_{1}, Y_{2}, \ldots, Y_{s}$ - as components of the random vector $Y$.

It is not possible to limit ourselves only to the analysis of separate initial and variable factors, characterising the quality of the risk management process in progress. It is because they are insufficient for obtaining comprehensive characteristics of the technical-economical indices of the risk management improvements process and it is impossible to define the optimal variant of the accident risk in the port and ports hinterland process management. The accident risk management process should be analysed as a multimeasurable process with a large number of initial parameters, the general assessment of which allows a complex evaluation of the efficiency of functioning of the technological ports operational process.

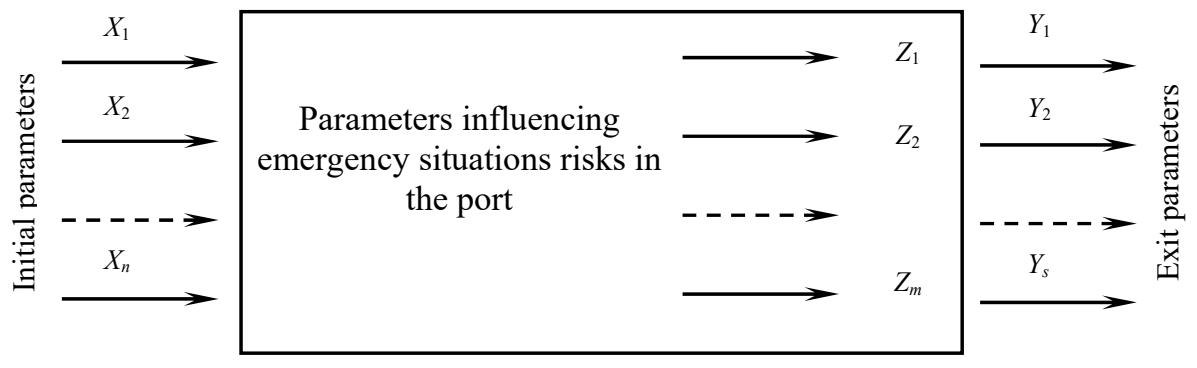

Figure 1. Scheme of the technological transportation process

It is obvious that according to the characteristics of the multimeasurable process, the meanings of every exit variable $Y$ should be defined. However, the exit variables of the multimeasurable process may be independent, correlated or connected by their functional interdependence. In practical terms, the characteristics of the risk management process should be analysed in each of the aforementioned cases. At the beginning we shall analyse the characteristics of the emergency situations risks process, when the initial variables $Y_{1}, Y_{2}, \ldots, Y_{s}$ are interdependent. 
normal

Let us presume that general probability density of the vectored random quantities $X, Z$ and $Y$ is

$$
\varphi_{t}\left(U_{1}, \ldots, U_{t}\right)=\frac{1}{\sigma_{u_{1}}, \ldots, \sigma_{u_{t}} \sqrt{(2 \Pi)^{t} E}} \times \exp \left\{\frac{-1}{2 E} \sum_{\mu, v=1}^{t} E_{\mu, v}\left(\frac{U_{\mu}-M\left\{U_{\mu}\right\}}{\sigma_{u \mu}}\right)\left(\frac{U_{v}-M\left\{U_{v}\right\}}{\sigma_{u v}}\right)\right\},
$$

where, for the sake of abridgement the random vector quantity $U$ is introduced, which is made of $X_{1}, \ldots$, $X_{n}, Z_{1}, \ldots, Z_{m}, Y_{1}, \ldots, Y_{s} ; t=n+m+s ; E-$ determinant of series t.

$$
E=\left|\begin{array}{cccc}
1 & \rho_{u_{1} u_{2}} & \cdots & \rho_{u_{1} u_{t}} \\
\rho_{u_{2} u_{1}} & 1 & \ldots & \rho_{u_{2} u_{t}} \\
\cdots & \ldots & \ldots & \ldots \\
\rho_{u+u_{1}} & \rho_{u+u_{2}} & \cdots & 1
\end{array}\right|
$$

or $X, Z, Y$ in the variables' marking

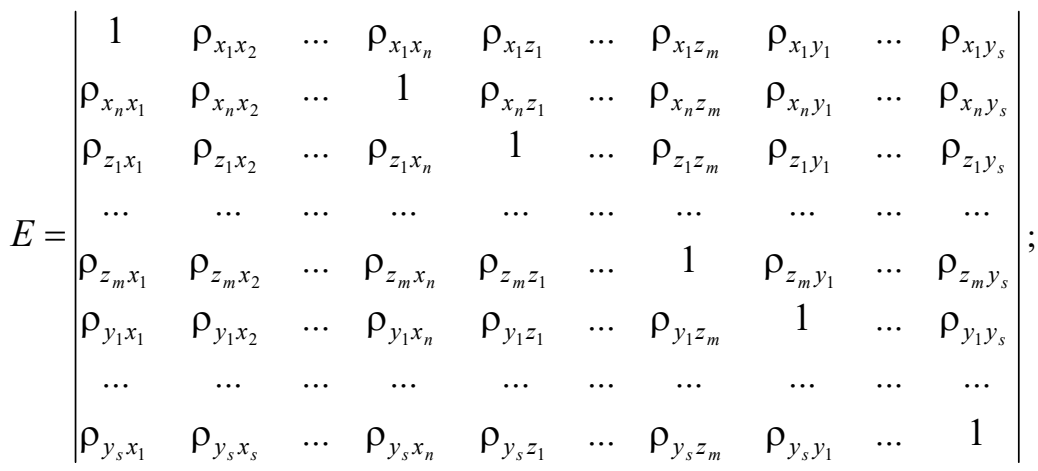

$E_{\mu \nu}$ is an algebraic supplement $\rho_{u m n v}$ in the determinant (2).

To analyse the case when the exit variables are independent, it is necessary to determine the characteristics of every variable $Y_{k}(k=1,2, \ldots, s)$ as well as the influence exercised on them by the initial variables $X$ and the variables $Z$, characterising the inner state of the process. Let us indicate the general probabilities' $X, Z$ and $Y$ density $Y_{n+m+1}\left(Y_{k}, X_{1}, \ldots, X_{n}, Z_{1}, \ldots, Z_{m}\right)$, whereas the random vectored quantities' $X$ and $Z$ by the general probability density $\varphi_{n+m}\left(X_{1}, \ldots, X_{n}, Z_{1}, \ldots, Z_{m}\right)$. The probability densities $\varphi_{n+m+1}\left(\varphi_{k}, X_{1}, \ldots, X_{n}, Z_{1}, \ldots, Z_{m}\right)$ and $\varphi_{n+m}\left(X_{1}, \ldots, X_{n}, Z_{1}, \ldots, Z_{m}\right)$ are not zero ones and they correspond to the equation (4.1) with determinants' $\sigma$ and $F$ meanings correspondingly of $(n+m+1)$, and the $(n+m)$ series

$$
\begin{aligned}
& \sigma=\left|\begin{array}{ccccc}
1 & \rho_{x_{1} x_{2}} & \ldots & \rho_{x_{1} z_{m}} & \rho_{x_{1} y_{k}} \\
\rho_{x_{2} x_{1}} & 1 & \ldots & \rho_{x_{2} z_{m}} & \rho_{x_{2} y_{k}} \\
\ldots & \ldots & \ldots & \ldots & \ldots \\
\rho_{z_{m} x_{1}} & \rho_{z_{m} x_{2}} & \ldots & 1 & \rho_{z_{m} y_{k}} \\
\rho_{y_{k} x_{1}} & \rho_{y_{k} x_{2}} & \ldots & \rho_{y_{k} z_{m}} & 1
\end{array}\right| ; \\
& F=\left|\begin{array}{ccccccc}
1 & \rho_{x_{1} x_{2}} & \ldots & \rho_{x_{1} x_{n}} & \rho_{x_{1} z_{1}} & \ldots & \rho_{x_{1} z_{m}} \\
\ldots & \ldots & \ldots & \ldots & \ldots & \ldots & \ldots \\
\rho_{x_{n} x_{1}} & \rho_{x_{n} x_{2}} & \ldots & 1 & \rho_{x_{n} z_{1}} & \ldots & \rho_{x_{n} z_{m}} \\
\rho_{z_{1} x_{1}} & \rho_{z_{1} x_{2}} & \ldots & \rho_{z_{1} x_{n}} & 1 & \ldots & \rho_{z_{1} z_{m}} \\
\ldots & \ldots & \ldots & \ldots & \ldots & \ldots & \ldots \\
\rho_{z_{m} x_{1}} & \rho_{z_{m} x_{2}} & \ldots & \rho_{z_{m} x_{n}} & \rho_{z_{m} z_{1}} & \ldots & 1
\end{array}\right| .
\end{aligned}
$$

A general characteristic of the technological emergency situations risks process is the conditional probability density $\varphi\left(Y_{k} /\left(X_{1}, \ldots, X_{n}, Z_{1}, \ldots, Z_{m}\right)\right)$, according to which the meaning may be defined by the 
general characteristics of the prior variables $X$ and the inner state variables $Z$ by transformation of the distribution laws of these random quantities.

For practical purposes it is often expedient to use digital characteristics instead of the random factors' distribution laws. Although the digital characteristics give insufficient information on random factors, they fully suffice for the solution of risk management issues, and their determination is far easier. A complete analysis and synthesis of the characteristics of the risk management processes is carried out according to general characteristics, i.e. according to the conditional and unconditional distribution laws. These laws may be employed for the definition of different characteristics of the technological port operational processes. However, as the formula presented shows, the characteristics of the technological risk management processes may be determined in such cases when the general laws of random quantities' distribution are known. This condition must be observed in designing systems for the accumulation and processing of statistical information.

\section{Groups of the Essential Emergency Situations Risk Indicators}

Investigation of transport flows through the BSR ports indicated that is essential conditionally resolve primary emergency risk indicators representing internal and external macro environment component into three groups: environment and nature, infrastructure and economic-organizational indicators (Bazaras and Palšaitis, 2016). Thus made expanded sets of typical indicators representing every basic group having most important international environment indicators influencing the transit potential and selected preliminary.

Table 1. Basic groups of the hazard and risk indicators in the port

\begin{tabular}{|c|c|}
\hline $\begin{array}{l}\text { A name of a } \\
\text { indicators group }\end{array}$ & The essential indicators of a group \\
\hline $\begin{array}{l}\text { Environment and } \\
\text { nature indicators }\end{array}$ & $\begin{array}{l}\text { Trade between East-West } \\
\text { Amount of cargo transportation using the BSR ports in the TEN-T corridors } \\
\text { Amount of cargo transportation through the separate port } \\
\text { Cargo transit transportation share of foreign transport companies through port } \\
\text { Transit transport flows spatial distribution } \\
\text { Other indicators }\end{array}$ \\
\hline $\begin{array}{l}\text { Infrastructure } \\
\text { indicators }\end{array}$ & $\begin{array}{l}\text { Main roads and rail network technical conditions in the port } \\
\text { Number of custom terminals in the port } \\
\text { Cranes and other cargo loading equipment capacity } \\
\text { Storage and warehouses capability } \\
\text { Port turnover capacity } \\
\text { Ports technical characteristics (depth of the port's channel and its configuration, the number of piers, } \\
\text { entry/exit duration and other) } \\
\text { Port's Internal transport routes } \\
\text { Internal and external data transfer facilities and communication equipment } \\
\text { Facilities and equipment for special cargo needs - danger cargo, military cargo, hazard materials, over-size } \\
\text { and heavy cargo } \\
\text { Rescue and fire extinguishing instruments. } \\
\text { Connections between different transport modes. }\end{array}$ \\
\hline $\begin{array}{l}\text { Organizational } \\
\text { indicators }\end{array}$ & $\begin{array}{l}\text { Number of structures responsible for transportation management in the port } \\
\text { Level of organization and coordination of transport flows in the port } \\
\text { Number of structures responsible for emergencies and accidents management in the port } \\
\text { Level of organization of emergencies and accidents management in the port and coordination between } \\
\text { structures } \\
\text { Technical equipage of structures responsible for emergencies and accidents management in the port } \\
\text { Port customs integration level into international custom information system } \\
\text { Other indicators }\end{array}$ \\
\hline
\end{tabular}

It must be noticed that remain possibility for the replenishment these groups with additional indicators. These indicators will reflect only in the occasion that their significance will be enough high. Part of these indicators may be defined for identification the transit status of the port and other part the emergency situations risks in the port.

During estimation of the ports hazard and risk management necessary to estimate not only environment and nature indicators, infrastructure indicators, organizational indicators, but indicators with are related with economic, social and political issues. Economic, social and political indicators could be divided to separate group and could be analysed as supporting force for main group of the technical- 
organizational indicators. The exclusive auxiliary indicators' group is a group of social indicators, since in it is possible to find indicators which have a direct impact on the staff behaviour which are working in the port. Personnel behavioural element may be one of the most significant in analysing and assessing the potential risks in the ports.

\section{Theoretical Background for the Multiple Criteria Evaluation}

It is necessary to analyze and to validate methods for quantitative evaluation and to formulate respective evaluation models (practice equations) for emergency situations risks.

Thus further analytic research is necessary to divert, when the theoretical basis (evaluation models) must be oriented towards preparation of multi-criteria evaluation methods.

The selection of multi-criteria evaluation methods depends from the complexity of assessment tasks and a wide spectre of their evaluation criteria. Many of those perspective methods depend to the group of decision making methods. It must be noted that the methods applied to the solution of those tasks and systems in general. In essence, the functional and relative models are applied, and the evaluation preconditions may be both determined and undetermined. In the last case, the in determination may result from unknown significance of the valuation criteria or by unknown either stochastic efficiency of those valuation criteria in case when they are determined.

The detailed analysis systemic publications of various authors permits to take into attention those of the evaluation methods' which may be potentially used more widely for the determining the compound magnitude. First of all we selected the evaluation methods group, as the most adequate to the formulated tasks. The Simple Additive Weighting (SAW) and Complex Proportional Assessment (COPRAS) methods attached to this group are mostly used for the determining of the compound magnitude. These multicriteria evaluation methods are detailed analysed by Ginevičius et al. (2008); Ginevičius and Podvezko (2005). Their peculiarities may be revealed by the specifies in the formation of criteria system evaluation, the determination of their criteria significance and the evaluation of the research object on this basis.

This corresponds to an offered three-stage compound quantitative assessment system on the basis SAW method, which enable to convert indicators primary indicators expressions to their assessment in 10 points scale (decimally). It is realized in the following consequence:

- the identification and expertise (quantifiable) assessment of primary indicators determining the selected groups, assessment their significances as well as ranking of primary indicators;

- the determination compound indexes of indicator groups as partial criteria for assessment generalize criterion - international environment index;

- the determination index international environment (as a composition of indicator groups) as a consolidated measure.

The expertise of the primary indicators and their weights using the provided technique is treated as a first stage of quantitative assessment. After all, this evaluation of emergencies risk evaluation system in the ports (applying quantitative methods and evaluation process algorithms) may be incorporated into the general transportation management system.

\section{Conclusions}

While assessing risks and emergency situations, the emphasis is placed on operators engaged in real activities - Seaports of the Baltic countries, where essential things can be done for scientific purposes - obtaining real data and modelling possible situations taking into account the specifics of ports' activities and distinctive character of operations. Moreover, expert opinion and an opportunity to evaluate the situation in a complex way is very important in analysing emergency situations since interinstitutional communication (institutions responsible for fire and rescue operations, activity planning, public relations and information management) is relevant for preventing certain situations to appear, as well as providing solutions to its consequences. The international project HAZARD, which is being implemented within the framework of the BSR INTERREG program, has well served for the assessment and analytics of these circumstances.

Ports activities management system interfaces with the indicators connected with the transportation safety and security in the port and are analyzed insufficiently.

Results of the scientific research suppose attitude that ports operational risk management system is very complexity and related with different fields of the influence - environment, infrastructure and organizational. Big amount of the different contradictory interests and impact points must be formalized 
for estimation and operations purposes. For this task it is recommended to use multi-criteria approach for the assessment emergency situations risks in the ports. It allows to formulate main risk groups components connections and evaluation principles considering their influence to transportation risk in the port management. Designed system of criteria creates a possibility for objective evaluation of risk management processes and allows planning objectively long-term risk management strategy in the ports according to certain economic development circumstances.

The creation of the methodology of the assessment emergency situations risks in the ports will support multimodal transport safety issues including prevention and elimination of undesirable events (failure, accident, collision, disaster), minimization of their appearance risk and mitigation of their consequences.

During estimation of the ports hazard and risk management all indicators could be divided in to two separated groups: technical-organizational which consist from environment and nature indicators, infrastructure indicators, organizational indicators and socio-economic indicators group, which are related with economic, social and political issues. The exclusive auxiliary indicators' group is a group of social indicators, since in it is possible to find indicators which have a direct impact on the staff behaviour which are working in the port. Personnel behavioural element may be one of the most significant in analysing and assessing the potential risks in the ports.

\section{References}

1. Batarliene, N. (2008) Risk analysis and assessment for transportation of dangerous freight. Transport, 23(2), 98-103. DOI: 10.3846/1648-4142.2008.23.98-103

2. Bazaras, D.; Palsaitis, R. (2011) The impact of the market structure on safety and security in BSR: Lithuania point of view. In: Proceedings of the 11th international conference Reliability and statistics in transportation and communication (RelStat'11), 19-22 October, 2011, Riga, Latvia.

3. Bazaras, D.; Batarliene, N.; Palšaitis, R.; Petraška, A. (2013) Optimal road route selection criteria system for oversize goods transportation. The Baltic Journal of road and bridge engineering, 8(1), 19-24. Vilnius: Technika. ISSN 1822-427X

4. Bazaras, D.; Palšaitis, R. (2016) Factors of emergency situations risks management in the BSR ports. Procedia Engineering, 178, 501-506. RelStat-2016: Proceedings of the 16th International Scientific Conference Reliability and Statistics in Transportation and Communication. Transport and Telecommunication Institute, Riga, Latvia. ISSN 1877-7058

5. Ginevichius, R.; Podvezko, V. (2005) Generation of a set of evaluation criteria. Business: theory and practice, 6(4), 199-207.

6. Ginevichius, R. Podvezko, V., Bruzge., S. (2008) Evaluating the effect of state aid to business by multi-criteria methods. Journal of Business Economics and Management, 9(3), 3-8.

7. Karlaftis, M. G. (2009) Ownership and competition in European transit: assessing efficiency. Transportmetrica, 5(2). DOI: 10.1080/ 1812860090303432

8. Lopez, E. Monzon, A., Ortega, E., Quitana, S.-M. (2009) Assessment of Cross-Border Spillover Effects of National Transport Infrastructure Plans: An Accessibility Approach. Transport Reviews, 29(4), 515-536.

9. Litvinenko, M.; Palsaitis, R. (2006) The evaluation of transit transport probable effects on the development of country's economy. Transport, 21(2), 135-140.

10. HAZARD project. Mitigating the Effects of Emergencies in the Baltic Sea Region Ports. INTERREG Baltic Sea Region programme project 2016-2019. Access via Internet: https://blogit.utu.fi/hazard/

11. Palsaitis, R.; Zvirblis, A. (2010) Multicriteria assessment of the international environment to the Lithuania road transport system for transit transport. In: Proceedings of the 14th international conference Transport Means-2010, pp. 85-88. October 21-22, 2010. Kaunas: Technologija, 2010. ISSN 1822-296X

12. Palukuri, S.; Jain, P. (2014) Operations in Disaster Management - Case Study Based Approach, [accessed 16 December 2015]. Available from Internet: http://www.mbaskool.com/businessarticles/operations/9351-operations-in-disaster-management-case-study-based-approach.html

13. Van Veen, B.A.D.; Vatvani, D.; Zijl, F. (2014) Tsunami Flood Modelling for Aceh \& West Sumatra and its Application for an Early Warning System. Continental Shelf Research, 79, 46-53.

14. White Paper. European transport policy for 2010: time to decide. Commission of the European Communities, Brussels, COM (2001) 370 final, 2001. 